\title{
Efficacy of Acceptance and Commitment Therapy in the Treatment of Social Phobia among Adolescents in Secondary Schools in Oyo State, Nigeria
}

\author{
Segun Oyetunde Babalola ${ }^{1}$, Ajibola Olusoga Ogunyemi ${ }^{2}$ \\ 1-Department of Educational Foundations and Counselling, Faculty of Education, Olabisi Onabanjo Unversity, Ago-Iwoye \\ ORCID ID: 0000-0003-2480-8445 \\ 2-Department of Psychology, Faculty of Social Sciences, Olabisi Onabanjo University, Ago-Iwoye \\ ORCID ID: 0000-0001-9969-4556 \\ Corresponding author contact: segunoyetunde9@gmail.com
}

\begin{abstract}
Social phobia is a mental health problem that has been repeatedly linked with adolescents. The main objective of the advanced paper, therefore, is to explore the efficacy of Acceptance and Commitment therapy (ACT) on social phobia among 13 secondary school adolescentsin the three senatorial districts of Oyo state, Nigeria. The research design adopted for the present study was a pretest-posttest control group quasi experimental layout. The sample comprised 104 secondary school adolescents that have been rated as experiencing different levels of social phobia from the two randomly selected schools among the three senatorial districts of Oyo State. The selected students, grouped by schools and subsequently, treatment groups, were 51 and 53 for the control and experimental groups, respectively. The experimentation spanned a period of eight weeks, with ACT administered to the experimental group and placebo of leadership styles administered to the control group. The Social Phobia Inventory (SPI) was adopted and used for screening and in pretest and posttest stages. A statistical hypothesis was formulated and tested at 0.05 level of significance by means of the Analysis of covariance (ANCOVA). It was found that treatment with ACT significantly reduced the level of social phobia among school-going adolescents. ACT was therefore recommended for use in relieving school-going adolescents suffering from social phobia.
\end{abstract}

Keywords: Acceptance and Commitment Therapy, Social Phobia, Secondary School Adolescents

\section{Introduction}

One of the mental health problems that have been linked with adolescence is social phobia, which is often called social anxiety disorder (SAD). It has been described to be prevalent among adolescents and this phenomenon is being considered as global issue.

Scholars like Schneier (1991) and Uzonwane(2014) observed that social phobia is a form of anxiety disorder that is not well understood by many people. Despite that, there is emerging information on its manifestation as one of the major psychological problems among adolescents. This situation also leads to poor personality development, which could follow adolescence to adulthood (Ogunleye, 2011).

Social phobia manifests as a fear of interacting and performing publicly which hinders the ability to eat, dance, speak or participate in various activities involving social interaction. This is noticed severely among secondary school adolescents during co-curricular activities such as, singing, debate and quiz competition; recitation exercises and games among others, which, in fact is in line with the definition of Encyclopedia of Mental Disorders (2014).

Kitchener, Jorm, and Kelly (2013) described social phobia as a situation that involves extreme discomfort or fear in a variety of social situations including speaking or eating in public, dating, and other types of social events. Other major symptoms of the disorder under consideration include dodging public responsibilities such as speech making, and isolation from the public places and peer groups. In fact, children or adolescents with social phobia are generally reserved. They become very uncomfortable when being watched under any form of performance such as writing, exhibition of talents and oth- 
er speech making programs. These are situations where public scrutiny may occur. Adolescents with social phobia are usually afraid of being embarrassed or humiliated in the way they behave.

Such disturbing experiences among adolescents require urgent attention due to the outcome of various findings on this phenomenon. For instance, Ryan and Warner (2013) stated that $6 \%$ of children and $12.1 \%$ of adolescents meet the diagnostic criteria for social phobia. Kessler, Burglund, Demler, Jin, Merikangas and Walters (2013) confirmed that social phobia starts as early as age 5 and is at its peak at around the of age 12. If social phobia is left untreated, it could lead to chronic problems at adolescence and eventually runs through adulthood (Ryan \&Warner, 2013). Harikrishnan, Ali, and Sobhana (2016) while quoting several authors (e.g., Beesdo, Knappe, \& Pine, 2009; Carta, Hardoy\&Cadeddu, 2004; Gren-Landellet al., 2009; Hitchcock, Chavira, \& Stein, 2009; Merikangaset al., 2010) affirmed that from the 1990s till the present, the incidence of social phobia is on the increase (Wittchen, Stein \& Kessler, 1999; Essau, Conradt\&Petermann, 1999; Ranta, Kaltiala-Heino, Rantanen\&Marttunen, 2009). This phenomenon could also contribute significantly to poor academic performance among adolescents and even affect their overall well-being.

In line with the aforementioned effects, scholars like Chhabra, Bhatia, Gupta, Kumar and Srivastva (2009) while citing Sarah (2006) reported that people suffering from social anxiety also have higher risk of developing other disorders like Obsessive compulsive disorder (OCD), anorexia nervosa, schizophrenia, depression, panic disorder, rumination and other forms of anxiety disorders. These disorders are also more common in the middle adolescence and childhood and their roots are closely linked with social phobia. Thus, lack of effective intervention strategies for timely treatment of anxiety disorders can make them persist throughout adulthood and the most dangerous aspect of it is that such a phenomenon can aggravate to suicidal attempts due to some of its comorbid conditions as stated above (Donald \&Oluyinka, 2017).

The intervention the present study brings into a sharper focus is that of the acceptance and commitment therapy (ACT) which is a cognitive-based strategy being investigated across the world among psychologists with empirical evidences of its effectiveness in treating various psychological disorders. According to Murrell, Al-Jabari, Moyer, Novamo and Connally (2016), ACT, which was developed by Hayes in the 1980s, has its basic principle on the assumption thateverybehavior is meant to serve a specific purpose, including avoidance of aversive stimuli in specific situations. This has made the therapy to be of great interest for researchers over the years (Guadiano, 2016). In an attempt to describe ACT, Hayes et al. (2001) stated that it stems from a philosophy of radical behaviorism based on the Relational Frame Theory (RFT) in line with B. F. Skinner's works.

ACT, based on the available evidence, has been regarded as a unique model for behavior change attributed to "contextual behavioural science" (Hayes, Levin, Plumb-Vilardaga, Villatte, \&Pistorello, 2013). Acceptance and Commitment Intervention, better known as Acceptance and Commitment Therapy (ACT) basically deals with developing the potential within the individual themselves to have the power and accept the reality of challenges that are beyond one's control and consistently commit to practices or activities that are capable of alleviating the situation in order to earn a better living. This can be achieved through psychological teaching and skills that could have direct effect on negative thoughts in one's life (Harris, 2006; Larmar, Wiatrowski and Lewis-Driver, 2014; Thus, ACT provides coping skills for individuals to face their psychological problems in a friendly manner and eventually, in the long run, to overcome such a problem. This approach to treating psychological disorder is associated with the principle of functional contextualism by Bigllan and Hayes (1996).

In the recent past, Tjak et al. (2015) has found ACT to be better than placebo and typical treatment for reducing substance addiction, depression and other psychological disorders. There is still not enough evidence for ACT to be effective in the treatment of social phobia in Nigeria, which, in turn, has raised serious methodological concerns. The study was accordingly designed to determine the efficacy of ACT in treating social phobia among secondary school adolescents in Oyo State.

\section{Hypothesis}

There is no significant effect of acceptance and commitment therapy on social phobia among inschool adolescents in Oyo State, Nigeria. 


\section{$3 \quad$ Method}

\subsection{Research Design and Participants}

Adopted in the study is a pretest-posttest control group quasi-experimental design. The independent variable refers to treatment, which exists at two levels (ACT and control). The dependent variable was respondents' social phobia. The sample comprised 120 adolescents in J.S.1-2 and S.S.1-2 from three public secondary schools in the three Senatorial Districts of Oyo State. (Oyo North, Oyo Central and Oyo South). However, on the whole, 107 secondary school adolescents were able to complete the entire treatment sessions. This implies that $10.8 \%$ mortality was recorded.

Multi-stage sampling procedure was used in selecting the sample comprising 120 adolescents. The first stage involved the use of the cluster random sampling technique to select three among the 33 Local Government Areas in the three Senatorial Districts. This was done through the simple random sampling technique.

In the next stage one secondary school has to be opted for from each selected Local Government Area through the simple random sampling technique. Subsequently, the Social Phobia Inventory (SPI) was thereafter used to screen 350 adolescents who manifested symptoms of social phobia. Selected, at the end, were those secondary school adolescents that scored 31 and above on the scale and fell within the range of having moderate to very severe social phobia. The last stage of the sampling process involved the use of the simple random sampling technique to select 60 respondents from the screened and the selected adolescents into each of the two treatment groups. Thus, there was a sample of 107 students in all.

\subsection{Measures}

The Social Phobia Inventory (SPI) developed by Davidson (2000) was adopted. It is a simple and self-rating scale that covers all the major social anxiety symptoms. The scale is divided into two sections $\mathrm{A}$ and $\mathrm{B}$.

Section A comprises age of the respondents and other demographic statistics and specifies the age as early adolescence (10-13) and late adolescence (14-17). It also indicates the gender; male (M) and female $(\mathrm{F})$. Section B comprises a 17-item scale rated on a five-point Likert format. Responses to the items range from $1=$ not at all to $5=$ extremely. Examples of the items in the inventory include: "I am afraid of people in authority"; "I avoid talking to people I don't know"; and "I avoid doing things or speaking to people for fear of embarrassment". The categorization of SPI connotes that the instrument demonstrates good test-retest reliability, while internal consistency using Cronbach's method was .85 and has been used in Nigeria by Uzonwanne (2014).

\subsection{Procedure for Data Collection}

Procedures for data collection were carried out in three stages: Pretest, treatment, and posttest. At the pretest, the researcher had interaction with the students and administration of the social phobia inventory was done to encompass all the students in JSS $1 \& 2$ and SS $1 \& 2$ for screening purpose. Students with high scores on the SPI were considered qualified to proceed to the treatment stage.

The treatment stage involved the administration of 8 weeks training sessions on intervention therapy (ACT) to the experimental group while participants in the control group were taught leadership styles for 8 weeks as placebo. Before the commencement of the training sessions, the researcher had a brief discussion with the participants as a way of introducing the steps involved in the therapies as well as the objectives of the training. The subjects in experimental group were subjected to Acceptance and Commitment therapy (ACT) on social phobia. Each session lasted for 30 minutes. The package for Acceptance and Commitment therapy was adapted from Slevison (2013) on effectiveness of acceptance and commitment therapy for worry and rumination. Refreshments were given to the participants at the end of each training session to strengthen their motivation. At posttest stage, both the experimental and control groups were administered with the SPI to determine the efficacy or effectiveness of the treatment. 


\subsection{Method of Data Analysis}

The data collected for both pretest and posttest was analyzed using Analysis of covariance (ANCOVA) and the hypotheses were tested at .05 level of significance. Inferences were made based on the specifications of Bamgboye et al (2005).

\section{$4 \quad$ Results}

The result in table 1 below shows that the experimental group (ACT) with a mean score $(\bar{x}=17.09)$ seemed to be more effective, against the Control group with the highest mean score $(\bar{x}=49.62)$. The smaller mean score of the experimental group implies that ACT has led to a reduction in the manifestation of social phobia among secondary school students when compared with the control group.

Table 1: Summary Statistics of Respondents by Treatment

\begin{tabular}{lcccc}
\hline \multirow{2}{*}{ Treatment } & \multirow{2}{*}{ Mean } & \multirow{2}{*}{ Std. Error } & \multicolumn{2}{c}{$\mathbf{9 5 \%}$ Confidence Interval } \\
\cline { 4 - 5 } & & & Lower Bound & Upper Bound \\
\hline Experimental Group & 17.093 & 0.826 & 15.461 & 18.726 \\
\hline Control Group & 49.623 & 1.281 & 47.092 & 52.154 \\
\hline
\end{tabular}

Table 2: Analysis of Covariance of Effect of ACT on Social Phobia

\begin{tabular}{|c|c|c|c|c|c|}
\hline \multicolumn{6}{|c|}{ Dependent Variable: POST TEST SCORE } \\
\hline Source & Type III Sum of Squares & Df & Mean Square & $\mathrm{F}$ & Sig. \\
\hline Corrected Model & 34097.936 & 2 & 17048.968 & 563.653 & 000 \\
\hline Intercept & 63.080 & 1 & 63.080 & 2.085 & 152 \\
\hline score1 & 2739.815 & 1 & 2739.815 & 90.580 & .000 \\
\hline Trt & 19787.508 & 1 & 19787.508 & 654.191 & .000 \\
\hline Error & 3054.977 & 101 & 30.247 & & \\
\hline Total & 145513.000 & 104 & & & \\
\hline Corrected Total & 37152.913 & 103 & & & \\
\hline
\end{tabular}

Table 2 reveals significant results $\left(\mathrm{F}_{(1,101)}=654.19, \mathrm{p}<0.05\right)$. Moreover, it can be inferred that there is a significant impact of the treatment on social phobia among secondary school adolescents. Still further, it signifies that the ACT could reduce social phobia among the participants. Accordingly, this also confirms the rejection of the null hypothesis at the stated significance level. Consequently, in order to determine the treatment group responsible for the observed significant difference among the treatment groups, the $\mathrm{K}$ matrix contrast is carefully considered and the result presented in Table 3. 
Table 3: Contrast Result (K Matrix)

Contrast Results (K Matrix)

TREATMENT Difference Contrast

Level 2 vs. Level 1

\begin{tabular}{ll} 
Contrast Estimate & \\
\hline \multicolumn{2}{l}{ Hypothesized Value } \\
\hline Difference (Estimate - Hypothesized) \\
\hline Std. Error \\
\hline Sig. \\
$\begin{array}{ll}95 \% \text { Confidence Interval for Differ- } & \text { Lower } \\
\text { ence } & \text { Bound } \\
& \begin{array}{c}\text { Upper } \\
\text { Bound }\end{array}\end{array}$
\end{tabular}

Dependent Variable

POST TEST SCORE $-30.183$ 0 $-30.183$

1.180 0.000

$-32.524$

In Table 3, the contrast estimate of the ACT-Control group comparison, which is approximately -30.183 , was observed to be statistically significant $(p<0.05)$. What this means is that the ACT treatment group has an average phobia score that is approximately 30.183 less than that of the control group.

\section{Discussion}

Results in this study revealed that ACT had significant effect on social phobia. The decrease in the post-test social phobia scores of the treatment group compared to their counterparts in the control group (as indicated in Tables 2and 3) showed that ACT was effective in treating social phobia among secondary school adolescents. The results of this study corroborated the past studies on the efficacy of ACT on various anxiety disorders and some other clinical conditions, such as worry and rumination, depression, chronic pain, etc. For example, the works of Hayes et al. (1999); Darlymle (2006) revealed acceptability and the effectiveness of ACT in treating social phobia among various participants to the extent that avoidance was significantly reduced. Also, the present study supports the earlier findings by Block (2002), which were consistent with the previous researches on ACT for anxiety disorders that there was a decreased experiential avoidance and increased willingness to experience anxiety during a public speaking exposure exercise. Therefore, acceptance and commitment therapy has been confirmed to have successfully decreased social phobia among adolescents, just as it was effective for treating other mental health challenges.

\section{Conclusion}

Little or no attention has been given to social phobia as one of the prevalent anxiety disorders among secondary school adolescents in Nigeria over the years and this could have detrimental effects on their lives and the future of the nation at large. This study has established the efficacy of ACT in treating social phobia among secondary school adolescents. It was concluded from the findings of this study that the use of ACT for treating social phobia among secondary school adolescents could make them become more self-confident and strong enough to live a better life. Therefore, it becomes very important for caregivers, counsellors and psychotherapists have their share in improving the use of ACT as an intervention that could be successfully deployed to drastically reduce the prevalence of social phobia among secondary school adolescents. 
It was also recommended that Secondary school adolescents should be encouraged and trained on the effective usage of ACT. This would make them adopt strategies to overcome social phobia and other anxiety disorders that might otherwise severely hamper their utmost performance.

Researchers and stakeholders should be ready to adopt the usage of other third generation psychotherapies like ACT, which seem to be more practicable and utilized by clients other than those receiving traditional cognitive restructuring therapy. Experts in Counselling/Educational Psychology should intensify efforts to organize seminars/conferences on the implications of this intervention as an effective measure in the treatment of social phobia among secondary school adolescents. Home (parents/guardians) and school management should work as a team towards reducing the incidence of social phobia among secondary school adolescents, which invariably will enhance their social and academic performances.

Policy makers and the general public should be aware of this intervention (ACT) and work towards its effective usage to reduce social phobia among adolescents in the society.

\section{References}

American Psychiatric Association. (2000) Diagnostic and statistical manual of mental disorders, (4th ed., text rev.). Washington, DC: American Psychiatric Association.

Bamgboye, E. A., Lucas, E. O., Agbeja, B. O., Ogunleye, B. O. \&Fawole, I. (2005). Statistical analysis and inferences.In A. I.Olayinka, V. O. Taiwo, A. Raji-Oyelade\& I. P. Farai (Eds.). Methodology of Basic and Applied Research. Ibadan: The Postgraduate School, University of Ibadan. ISBN: 978-37883-9-6.

Beesdo K., Knappe S., \& Pine, D.S. (2009) Anxiety and anxiety disorders in children and adolescents: Developmental issues and implications for DSM-V. Psychiatric Clinics of North America; 32(3):483-524. https://doi.org/10.1016/j.psc.2009.06.002

Biglan, A. \& Hayes, S.C. (1996) Should the Behavioral Sciences Become more Pragmatic? The Case for Functional Contextualism in Research on Human Behavior.Applied and Preventative Psychology: Current Scientific Perspectives, 5, 47-57. https://doi.org/10.1016/S0962-1849(96)80026-6

Block, J. A. (2002). Acceptance or change of private experiences: A comparative analysis in college students with public speaking anxiety. Doctoral dissertation. University at Albany, State University of New York

Carta, M.G., Hardoy, M. C. \&Cadeddu, M. (2004) Social phobia in an Italian region: Do Italian studies show lower frequencies than community surveys conducted in other European countries. BMC Psychiatry; 4(31): 1-6. 20. https://doi.org/10.1186/1471-244X-431

Chhabra, V., Bhatia, M. S., Gupta, S., Kumar, P., \& Srivastava, S. (2009). Prevalence of social phobia in school-going adolescents in an urban area.Delhi Journal of Psychiatry $12(1), 18-22$.

Donald, C. C. \& Oluyinka, O. (2017) Prevalence and correlates of social phobia and its impact on the academic performance of university students at a tertiary hospital in Nige- 
ria. International Journal of Medical Research and Pharmaceutical Sciences. 4(4): ISSN: 2394-9414

Essau, C. A., Conradt, J., \&Petermann, F. (1999). Frequency and comorbidity of social phobia and social fears in adolescents.Behaviour Research and Therapy, 37(9), 831-843. https://doi.org/10.1016/S0005-7967(98)00179-X

Gaudiano, B.A. (2016): Evaluating Acceptance and Commitment Therapy: An Analysis of a Recent Critique IJBCT Consolidated 5,(3\& 4):311. https://doi.org/10.1037/h0100891

Gren-Landell, M., Tillfors, M., Furmark, T., Rohlin, G., Anderson, G. \&Svedin C.G. (2009) Social phobia in Swedish adolescents: Prevalence and gender differences.Soc Psychiatry PsychiatrEpidemiol, 44(1): 1-7. 21. https://doi.org/10.1007/s00127-008-0400-7

Harikrishnan, U., Ali, A. \&Sobhana, H (2016), Prevalence of Social Phobia among School Going Adolescents, International Journal of Indian Psychology, 3, (4),74, ISSN:2348-5396 (e), ISSN:2349-3429 (p), DIP:18.01.039/20160304, ISBN:978-1$365-46362-4$

Harris, R. (2006) Embracing Your Demons: An Overview of Acceptance and Commitment Therapy. Psychotherapy in Australia, 12, 2-8.

Hayes, S.C., Levin, M.E., Plumb-Vilardaga, J., Villatte, J.L. and Pistorello, J. (2013) Acceptance and Commitment Therapy and Contextual Behavioral Science: Examining the Progress of a Distinctive Model of Behavioral and Cogni- tive Therapy. Behavior Therapy, 44, 180-196. https://doi.org/10.1016/j.beth.2009.08.002

Hayes, S. C., Strosahl, K. D., \& Wilson, K. G. (1999). Acceptance and commitment therapy: An experiential approach to behavior change. New York: Guilford.

Hitchcock C. A, Chavira D.A. \&Stein M.B., (2009). Recent findings in social phobia among children and adolescents.Israel Journal of Psychiatry \& Related Sciences 2009; 46(1):34-44.

Kessler, R.C., Burglund, P., Demler, O., Jin, R., Marikangas, K. R., \& Walters E. E. (2005). Lifetime prevalence and age-of-onset distribution of DSM-IV Disorders in the National Comorbidity survey replication. Archives of General psychiatry; 62(6): 593-605. https://doi.org/10.1001/archpsyc.62.6.593

Kitchener, B. A., Jorm, A. F., \& Kelly C. (2013). Mental health first aid manual. $3^{\text {rd }}$ ed.melbourne: mental health first aid, Australia.

Larmar, S., Wiatrowski, S. and Lewis-Driver, S. (2014) Acceptance \& Commitment Therapy: An Overview of Techniques and Applications.Journal of Service Science and Management, 7,216-221 https://doi.org/10.4236/jssm.2014.73019

Mental Disorders (2014). Social phobia. Encyclopedia of Mental Disorders. Retrieved from http://www.minddisorders.com/Py-Z/Social-phobia.html 
Merikangas, K., He J., Burstein, M., Swanson S. A.,\&Avenevoli S., Cui L., Benjet C., Georgiades, K. \&Swendsen J. (2010) Lifetime prevalence of mental disorders in U.S. adolescents: Results from the National Comorbidity Study Adolescent Supplement (NCSA). Journal of America Academics Child Adolescence Psychiatry 2010 Oct; 49(10):980-989. https://doi.org/10.1016/j.jaac.2010.05.017

Murrell, A. R., Al- Jabari, R., Moyer, Novano, E. \&Connally M.E. (2016) An Acceptance and Commitment Therapy Approach to adolescents Suicide. University of North Texas, USA

National Institute of Mental Health (2009). The numbers count: Mental disorders in America. NIMH.

Ogunleye, B. O. (2011). "Team pair solo" cooperative learning and personality type as determinants of students' achievement and attitude to Chemistry. African Research Review 5 (6): 259-276. https://doi.org/10.4314/afrrev.v5i6.22

Ranta, K., Kaltiala-Heino, R., Rantanen, P. \&Marttunen, M. (2009): Social phobia in Finnish general adolescent population: prevalence, comorbidity, individual and family correlates, and service use. Depress Anxiety, 26: 528-536. https://doi.org/10.1002/da.20422

Ryan, J. L. \& Warner, C.M. (2013). Treating adolescent with social anxiety disorders in schools. https://www.ncbi.nlm.nih.gov/pmc/articles/PMC3259736/

Schneier, F. R. (1991). Social Phobia. Psychiatric Annals 21(6):349-353 https://doi.org/10.3928/0048-5713-19910601-07

Skinner, B. F. (1957). Verbal Behavior. New York: Appleton-Century-Crofts. https://doi.org/10.1037/11256-000

Tjak, A., Davis, M. L., Morina, N., Powers, M. B., Smits M. \&Emmelkamp, P. M. (2015). A meta-analysis of the efficacy of acceptance and commitment therapy for clinically relevant mental and physical health problems. http://www.ncbi.nlm.nih.gov/m/pubmed/25547522/

Uzonwanne, F. C. (2014). Prevalence of Social Phobia, Gender and School Type among Young Adults in Nigerian Universities; Journal of Research in Humanities and Social Science, 2 (8) pp: 36-45 ISSN(Online) 2321-9467

Wittchen, H., Stein, M., \& Kessler, R. (1999). Social fears and social phobia in a community sample of adolescents and young adults: Prevalence, risk factors and co-morbidity. https://doi.org/10.1017/S0033291798008174 